\title{
Intravenous Barbiturate Overdose
}

\section{Euthanasia}

National Cancer Institute

\section{Source}

National Cancer Institute. Intravenous Barbiturate Overdose Euthanasia. NCI Thesaurus.

Code C90401.

A method of euthanization whereby a subject is anesthetized and barbiturate(s) are administered intravenously to induce respiratory arrest. 